\title{
浙江普陀山岛森林凋落物动态与微气候的关联性
}

\author{
宋彦君 ${ }^{1,2,3}$ 田文斌 ${ }^{4}$ 刘翔宇 $1,2,3$ 尹 芳 $1,2,3$ 程浚洋 $1,2,3$ 朱丹妮 $1,2,3$ \\ ARSHAD $^{1,2,3}$ 阎恩荣 $1,2,3 *$ \\ 1华东师范大学生态与环境科学学院, 上海 200241; ${ }^{2}$ 浙江普陀山森林生态系统定位观测研究站, 浙江舟山 316100; ${ }^{3}$ 浙江天童森林生态系统国家野外 \\ 科学观测研究站, 浙江宁波 315114; ${ }^{4}$ 普陀山园林管理中心, 浙江舟山 316100
}

摘 要 森林调落物动态是森林生态系统过程中的重要组成部分, 探索森林调落物动态特征与微气候间的关系, 对深入了解 生态系统变化过程运行机理具有重要意义。该研究以浙江普陀山岛典型森林类型枫香(Liquidambar formosana)林、天竺桂 (Cinnamomum japonicum)+红楠(Machilus thunbergii)林、马尾松(Pinus massoniana)林、青冈(Cyclobalanopsis glauca)林、台湾 蚊母树 (Distylium gracile) 林为研究对象, 探究森林调落量与微气候的关系。结果表明: 1) 森林年调落量介于3.45-5.36 $\mathrm{t} \cdot \mathrm{hm}^{-2} \cdot \mathrm{a}^{-1}$, 年调落量各组分比例表现出不同的组成特征, 森林类型与森林月调落量无关。2)森林月调落量动态模式主要呈双 峰型和三峰型, 调落峰值和风速峰值趋势相一致, 主要集中在台风干扰较大的4、7、12月份。3) 几余分析结果表明, 影响不 同组分月调落量的微气候因子不同: 月总调落量、叶调落量、果调落量和碎屑调落量的主要控制因素均为空气温度, 随空气 温度的升高而增大; 枝调落量的主要影响因素是森林上层风速, 同样起着显著的正向作用; 花调落量与空气湿度之间呈负相 关关系。森林年调落量各组分所占比例存在差异, 森林月调落量和森林类型无关, 主要与空气温度、空气湿度、森林上层风 速等微气候因子有关。

关键词 普陀山岛; 调落量; 调落物动态; 咒余分析; 微气候

引用格式: 宋彦君, 田文斌, 刘翔宇, 尹芳, 程浚洋, 朱丹妮, Ali ARSHAD, 阎恩荣 (2016). 浙江普陀山岛森林调落物动态与微气候的关联性. 植物生 态学报, 40, 1154-1163. doi: 10.17521/cjpe.2016.0157

\section{Associations between litterfall dynamics and micro-climate in forests of Putuoshan Island, Zhejiang, China}

SONG Yan-Jun ${ }^{1,2,3}$, TIAN Wen-Bin ${ }^{4}$, LIU Xiang-Yu ${ }^{1,2,3}$, YIN Fang ${ }^{1,2,3}$, CHENG Jun-Yang ${ }^{1,2,3}$, ZHU Dan-Ni ${ }^{1,2,3}$ Ali ARSHAD $^{1,2,3}$, and YAN En-Rong ${ }^{1,2,3^{*}}$

${ }^{1}$ School of Ecological and Environmental Sciences, East China Normal University, Shanghai 200241, China; ${ }^{2}$ Putuo Forest Ecosystem Research and Observation Station, Zhoushan, Zhejiang 316100, China; ${ }^{3}$ Tiantong National Forest Ecosystem Observation and Research Station, Ningbo, Zhejiang 315114, China; and ${ }^{4}$ Center of Garden Management in Putuoshan, Zhoushan, Zhejiang 316100, China

\section{Abstract}

Aims Seasonal litterfall production plays an important role in the carbon and nutrient cycling in forest ecosystems. This study examines the effects of micro-environmental factors on seasonal litterfall dynamics in the forests of Putuoshan Island, Zhejiang Province of eastern China.

Methods The study covers five forest types, including Liquidambar formosana forest, Cinnamomum japonicum and Machilus thunbergii forest, Pinus massoniana forest, Cyclobalanopsis glauca forest, and Distylium gracile forest, in Putuoshan Island. We collected micro-meteorological data, and measured monthly litterfall in stands of the five forest types over one year. Redundancy analysis (RDA) was performed to determine the effects of micro-climatic factors on litterfall production.

Important findings The average annual litterfall production ranged from 3.45 to $5.36 \mathrm{t} \cdot \mathrm{hm}^{-2} \cdot \mathrm{a}^{-1}$ across five types of forests, albeit no effect of forest types on the litterfall production. The partitioning of litterfall components differed among the five forest types. The seasonal litterfall production exhibited two contrasting patterns, i.e. double climax curve and triple peaks, and varied significantly among the five forest types. Moreover, the peak in the litterfall production mostly occurred in the windy months of the year, such as in April, July and December, which was consistent with the dynamics of wind speed. RDA results showed that components of litterfall production in different months were controlled by different micro-climatic factors. The total, leaves, fruits, and

收稿日期Received: 2016-05-05 接受日期Accepted: 2016-09-21

* 通信作者Author for correspondence (E-mail: eryan@des.ecnu.edu.cn) 
miscellaneous litterfall productions were directly and positively affected by air temperature. Twig litterfall production was positively affected by the overstory wind velocity. Flower litterfall production was negatively affected by air humidity. In summary, forest types had no effects on litterfall production. However, variations in litterfall productions were explained by air temperature, air humidity, and overstory wind velocity in the forests studied.

Key words Putuoshan Island; litterfall production; litterfall dynamics; redundancy analysis; micro-climate

Citation: Song YJ, Tian WB, Liu XY, Yin F, Cheng JY, Zhu DN, Arshad A, Yan ER (2016). Associations between litterfall dynamics and micro-climate in forests of Putuoshan Island, Zhejiang, China. Chinese Journal of Plant Ecology, 40, 1154-1163. doi: 10.17521/cjpe.2016.0157

森林调落物在森林生态系统碳循环和养分循环 过程中发挥着重要的作用(Xu et al., 2004), 其变化 不仅与物种生理生态特性、物种遗传特性、林龄、 森林类型和森林发育节律等生物因子有关, 还与气 温、降雨、台风、光照等非生物因子有关(郑征等, 2005; Thuille \& Schulze, 2006; Olena \& Nedret, 2007; Scherer-Lorenzen et al., 2007; 宁晓波等, 2009)。因此, 研究这些因素如何控制森林调落量对 于理解森林生态系统过程具有重要意义。

森林调落量是指单位时间、单位面积上林地所 有调落物的总量, 是研究物质循环以及养分归还过 程中的重要基础数据(Running \& Hunt, 1993; Friend et al., 1997; Wang et al., 2016)。以往的研究主要集中 在凋落物动态、组成、与调落物氮磷养分浓度相结 合计算养分归还量等方面, 而对森林调落量本身的 控制因素研究较少(徐旺明等, 2013; 马文济等, 2014)。森林调落量主要与调落节律有关, 而气候因 子是影响凋落节律的一个重要因子(郑征等, 2005; 张晴晴等, 2016)。一般而言, 森林调落量随着温度、 风速、湿度以及降雨的增大而增大(Liu et al., 2004; 邹碧等, 2006)。近年来, 国内外开展了大量关于气 候因子与调落量关系的研究, 极大地提高了我们对 森林生态系统应对环境变化响应过程的认识, 但这 些研究仍存在一些不足之处。例如, 多数研究仅仅 从单因子角度出发考虑气候对调落物的影响, 并未 充分反映出多因子条件对调落物的影响机制(邹碧 等, 2006; 张新平等, 2008)。大量研究往往集中于森 林总调落量, 而不同器官对气候的响应可能存在差 异(Liu et al., 2004; Sharma et al., 2012)。此外, 森林 调落量对气候的响应存在明显的时空差异, 大量研 究发现不同尺度的研究结果存在较大的异质性 (Sharma et al., 2012; Zhang et al., 2014), 少数研究 发现森林调落量不受微气候因素的影响(Berg \&
Meentemeyer, 2001; Hoque et al., 2015)。因此，全面 系统地探讨、评估森林调落物与气候之间的关系, 对进一步探索和完善森林生态系统与陆地环境之间 的相互作用过程有着重要的理论和现实意义。

海岛作为一种特殊的生态系统, 兼具海陆双重 特性, 同时表现出一定的特殊性和多变性(池源等, 2015)。与大陆生态系统相比, 海岛森林生态系统极 易受到洋流、季风以及人为干扰因素的影响, 对生 态环境变化具有更强的敏感性。海岛环境频繁的干 扰事件, 如台风、干旱和虫害等, 不仅严重威胁着生 态系统的服务功能, 同时也对森林生态的稳定性和 多样性产生着重要影响(Brando et al., 2008; Lovett et al., 2010; Lin et al., 2011)。作为指示森林生态系统 物质循环和能量流动的重要指标, 森林调落物在水 源涵养、水土保持、养分供应以及生物固碳等方面 发挥着重要的作用(Liski et al., 2003)。已有研究表 明, 不同区域森林凋落物对气候变化的响应存在差 异, 这种差异可能是由于微气候所导致的(Wang et al., 2016)。不同微气候条件下, 不同气候因子(如风 速、温度和湿度)之间的相互作用存在显著差异, 直 接或间接地调控着森林调落物的时空分布格局。因 此, 探讨海岛微气候对森林调落物的影响规律, 对 于评价森林生态系统对气候变化的响应特征以及科 学管理和利用森林生态系统具有重要作用。

普陀山岛隶属于中国最大的群岛一舟山群 岛, 具有典型的海岛森林群落。岛内森林资源丰富, 森林覆盖率高, 主要以常绿阔叶林、落叶阔叶林、 常绿落叶阔叶混交林和针叶林为主, 该岛四周环海, 气候复杂多样, 雨量丰沛, 空气湿度大, 台风频发, 风速较大(赵慈良等, 2009)。森林类型和微气候可能 是森林调落量的重要影响因素。基于此, 本研究以 岛上5种典型森林为对象, 以一年为时间尺度, 探讨 海岛微气候和森林凋落物的相互作用关系, 揭示森 
林调落物对气候变化的响应规律, 尝试从区域生态 系统尺度上探讨如下问题: (1)调落物产量及其组分 结构是怎样的? (2)调落物月度动态特征如何? (3) 有哪些微气候因素影响月度调落量及其组分结构? (4)不同林型的调落量及其微气候驱动因素是否相 同? 对上述问题的回答, 有助于我们全面理解海岛 地区森林调落量特征及其与微气候之间的相互关 系, 揭示由微气候引起的调落量变化的驱动机制。

\section{1 材料和方法}

\section{1 研究区概况和样地选择}

研究地位于浙江省舟山市普陀山岛 (29.97$30.03^{\circ} \mathrm{N}, 122.38^{\circ} \mathrm{E}$ ), 面积约 $12.5 \mathrm{~km}^{2}$, 位于杭州湾 南缘, 舟山群岛东部海域。该地区气候属于季风海 洋性气候, 年平均气温 $16{ }^{\circ} \mathrm{C}$, 冬暖夏凉; 最热月 8 月, 平均气温 $27{ }^{\circ} \mathrm{C}$; 最冷月 1 月, 平均气温 $5.4{ }^{\circ} \mathrm{C}$; 年降水量927-1 $620 \mathrm{~mm}$, 年平均相对湿度 $80 \%$, 年 无霜期251-303天。(钱逸凡等, 2012)

据资料记载和野外调查, 台湾蚊母树(Distylium gracile)群落、聯木(Loropetalum chinensis)群落、红 山茶(Camellia longicaudata)群落等为普陀山岛特殊 的森林类型。在中国和浙江植被划分中, 普陀山岛植 被属“中亚热带常绿阔叶林北部亚地带”的浙闽山丘 甜槠(Castanopsis eyrei)-木荷(Shima superba)林区中 天台、括苍山山地丘陵、岛屿植被片 ${ }^{1}$ 。研究区域物 种丰富, 但由于较早的人类活动干扰，原始植被破 坏较为严重, 仅一批典型的常绿阔叶林和古树名木 由于得到寺庙的庇护而较好地保存下来(钱逸凡等, 2012)。考虑到人为干扰和植被退化的现状, 在样地 选择时, 以成熟林为参照, 选取枫香 (Liquidambar formosana)林、天竺桂(Cinnamomum japonicum)+红楠 (Machilus thunbergii)林、马尾松(Pinus massoniana) 林、青冈(Cyclobalanopsis glauca)林和台湾蚊母树 (Distylium gracile)林代表5种不同森林类型, 地理位 置分别为半山庵、洛迦山、杨枝庵、天竺山庄和佛 顶山寺庙附近。各群落类型特征详见表1。

\section{2 凋落物收集}

2015年2月至2016年1月, 对5种森林群落的调 落物进行收集, 每种森林随机设置3个20 m × $20 \mathrm{~m}$

(1) 王国明 (2013). 舟山海岛典型植被类型的群落结构特征. 见: 生态 文明建设中的植物学: 现在与未来一中国植物学会第十五届会员代表 大会暨八十周年学术年会论文集一第 2 分会场: 植物生态与环境保护. 北京.

www.plant-ecology.com
重复样地, 每个样地均匀放置5个调落物筐。调落物 筐是由PVC管支撑、铁丝和尼龙纱网围成的 $1 \mathrm{~m} \times 1$ $\mathrm{m}$ 的正方形网面构成, 网眼大小为 $0.2 \mathrm{~mm}$, 纱网底部 保持在距地面 $10 \mathrm{~cm}$ 以上。每月定期收集筐中的调落 物, 于实验室内将调落物进一步分为叶、枝、花、果、 树皮及动植物残体等碎屑。同时，将分类后的各组分 置于70 ${ }^{\circ} \mathrm{C}$ 烘箱烘干至恒质量后称质量并记录。

\section{3 群落微气候监测}

于2015年1月在5种森林类型中安装Decagon微 型气象监测系统(EM50, Decagon, Pullman, USA), 该系统主要由风速风向传感器、VP-4空气温湿度和 5-TE土壤温湿度传感器构成。基于群落高度设置了 4 个高度梯度记录微气候, 从第一层到第四层依次 为: 2.5-3.0 m、5.5-7.5 m、7.5-12.0 m、12.0-16.5 m。 其中, 空气温度仪安装在第一、三、四层, 空气湿度 仪仅在第一和第三层安装。第一层的风速值代表森 林下层的风速，第四层的风速值代表森林上层的风 速。数据记录间隔设定为 $30 \mathrm{~min}$, 每月定期下载数 据并对仪器进行维护。

\section{4 数据处理及统计分析}

每一森林类型的调落量用 3 个样地的平均值表 示。每块样地每月从 5 个收集框中收集的森林调落量 取平均值, 获得该样地月调落量, 年调落量为 12 个 月内凋落物各组分之和。分析微气候时, 空气温度 和空气湿度均为所记录数据的月平均值。本研究共 收集 12 个月的调落数据和气象数据, 即 2015 年 2 月 份至翌年1月份的调落量数据及环境数据。

另外, 采用圥余分析(RDA)方法检测森林月总调落 量及各组分调落量与微气候因子(包括空气温度、空 气湿度、土壤温度、土壤湿度、森林上层风速和森 林下层风速6种变量)之间的关系。首先对森林凋落 量进行去趋势对应分析(DCA), DCA 结果得到各排 序轴最大的梯度长度均小于 3 , 说明适合用线性响 应模型进行圥余分析。在进行微气候变量的RDA分 析之前, 需要考虑自变量(即微气候因子)之间的共 线性问题, 去除方差膨胀系数大于 10 的微气候因子 (Gross, 2003), 剩下空气温度、空气湿度、土壤湿度、 森林上层风速、森林下层风速5种变量。RDA通过 各组分调落量和气候因子 2 个变量集的线性关系模 型, 得到数值矩阵并对特征值进行分解, 能将表征 森林凋落量的指标及微气候因子之间的关系反映在 坐标轴上, RDA分析结果的显著性水平经过999次 
的排列检验(Legendre et al., 2011)。最后采用方差分 解(VAR)得出气候因子对月调落量各组分的方差解 释量。方差分解和午余分析在R 3.3.0软件的“vegan” (Oksanen et al., 2007)程序包中完成。

\section{2 结果和分析}

\section{1 不同森林年凋落量与组分特征}

5种森林年调落量介于 $3.45-5.36 \mathrm{t} \cdot \mathrm{hm}^{-2} \cdot \mathrm{a}^{-1}$, 绝 对值大小依次为: 台湾蚊母树林 $((5.36 \pm 1.25)$ $\left.\mathrm{t} \cdot \mathrm{hm}^{-2} \cdot \mathrm{a}^{-1}\right)>$ 马尾松林 $\left((3.99 \pm 0.50) \mathrm{t} \cdot \mathrm{hm}^{-2} \cdot \mathrm{a}^{-1}\right)>$ 青冈 林((3.88 \pm 0.31$\left.) \mathrm{t} \cdot \mathrm{hm}^{-2} \cdot \mathrm{a}^{-1}\right)>$ 天竺桂+红楠林((3.83 \pm $\left.0.66) t \cdot h m^{-2} \cdot a^{-1}\right)>$ 枫香林((3.45 \pm 0.42$\left.) t \cdot h m^{-2} \cdot a^{-1}\right)$, 台 湾蚊母树林年凋落量最大。但是, 结果表明森林类型 对森林月总调落量无显著影响 $(F=0.05, p=0.83)$ 。

调落叶在调落物中占最大比重, 其所占比例介 于 $68.23 \%$ (枫香林)和 $82.85 \%$ (青冈林)之间; 调落枝 的比例最小值3.72\%出现在马尾松林, 最大值比例 出现在台湾蚊母树林, 为 $18.21 \%$; 调落花的比例较 低, 大小介于 $1.08 \%$ (台湾蚊母树林)和 $4.95 \%$ (天竺 桂+红楠林); 调落果的比例变化较大, 大小介于
2.17\% (青冈林)和14.05\% (枫香林)之间; 碎屑在枫 香林中比例最低, 为 $4.27 \%$, 马尾松林最高, 为 $9.08 \%$ (表2)。

\section{2 森林凋落量月动态特征}

5 种森林调落量具有明显的月际变化规律(图 1)。5种森林调落物调落高峰期均在7月份。其中, 枫 香林、天竺桂+红楠林和青冈林为双峰型凋落模式, 马尾松林和台湾蚊母树林为三峰型调落模式。枫香 林和青冈林有7月份和4月份两个调落高峰期, 最高 峰均出现在4月份; 天竺桂+红楠林的调落峰值出现 在5月份和 7 月份, 而7月份为调落的最高峰期; 马 尾松林和台湾蚊母树林比青冈林和枫香林多了一个 12月份的峰值, 最高峰出现在7月份。

各组分调落高峰存在较小差异, 叶调落峰值主 要出现在4、5、7和12月份; 枝调落最高峰主要为7 月份; 花调落高峰主要集中在 4 月份, 果和碎屑调 落高峰差异较大(图1)。

\subsection{5 种森林微气候的月动态特征}

由图2可知, 空气温度和土壤温度在8月份达到 峰值, 风速与森林调落峰值大体一致, 主要集中在

表1 浙江普陀山岛5种森林类型的样地特征

Table 1 Characteristics of the five forest types in Putuoshan Island, Zhejiang, East China

\begin{tabular}{|c|c|c|c|c|c|c|c|}
\hline $\begin{array}{l}\text { 森林类型 } \\
\text { Forest type }\end{array}$ & $\begin{array}{c}\text { 年龄 } \\
\text { Age (a) }\end{array}$ & $\begin{array}{c}\text { 海拔 } \\
\text { Altitude (m) }\end{array}$ & $\begin{array}{l}\text { 坡度 } \\
\text { Slope }\end{array}$ & $\begin{array}{c}\text { 坡向 } \\
\text { Aspect }\end{array}$ & $\begin{array}{c}\text { 群落高度 } \\
\text { Community height (m) } \\
\end{array}$ & $\begin{array}{c}\text { 盖度 } \\
\text { Coverage (\%) } \\
\end{array}$ & $\begin{array}{l}\text { 优势树种 } \\
\text { Dominant tree species }\end{array}$ \\
\hline $\begin{array}{l}\text { 枫香林 } \\
\text { Liquidambar formosana forest }\end{array}$ & 50 & 65 & $19^{\circ}$ & 东南 SE & 13.5 & 70 & $\begin{array}{l}\text { 枫香 Liquidambar formosana } \\
\text { 麻栋 Quercus acutissima } \\
\text { 樟树 Cinnamomum camphora }\end{array}$ \\
\hline $\begin{array}{l}\text { 天竺桂+红楠林 } \\
\text { Cinnamomum japonicum+ } \\
\text { Machilus thunbergii forest }\end{array}$ & 80 & 70 & $15^{\circ}$ & 西 W & 9.5 & 100 & $\begin{array}{l}\text { 红楠 Machilus thunbergii } \\
\text { 天竺桂 Cinnamomum japonicum }\end{array}$ \\
\hline $\begin{array}{l}\text { 马尾松林 } \\
\text { Pinus massoniana forest }\end{array}$ & 40 & 50 & $14^{\circ}$ & 东北 NE & 13.5 & 80 & $\begin{array}{l}\text { 马尾松 Pinus massoniana } \\
\text { 石栋 Lithocarpus glabra } \\
\text { 青冈 Cyclobalanopsis glauca }\end{array}$ \\
\hline $\begin{array}{l}\text { 青冈林 } \\
\text { Cyclobalanopsis glauca forest }\end{array}$ & 60 & 153 & $15^{\circ}$ & 东北 NE & 8.5 & 90 & $\begin{array}{l}\text { 青冈 Cyclobalanopsis glauca } \\
\text { 石栋 Lithocarpus glaber }\end{array}$ \\
\hline $\begin{array}{l}\text { 台湾蚊母树林 } \\
\text { Distylium gracile forest }\end{array}$ & 160 & 241 & $8^{\circ}$ & 东北 NE & 9.6 & 100 & $\begin{array}{l}\text { 台湾蚊母树 Distylium gracile } \\
\text { 铁冬青 Ilex rotunda } \\
\text { 红楠 Machilus thunbergii } \\
\text { 红山茶 Camellia longicaudata }\end{array}$ \\
\hline
\end{tabular}

NE, northeast; SE, southeast; W, west.

表2 浙江普陀山岛 5 种森林凋落物各组分年调落量 $\left(\mathrm{t} \cdot \mathrm{hm}^{-2} \cdot \mathrm{a}^{-1}\right)$ 及其占总凋落量的比例(括号中的数字为百分比, \%)

Table 2 Characteristics of annual productions $\left(\mathrm{t} \cdot \mathrm{hm}^{-2} \cdot \mathrm{a}^{-1}\right)$ of different litterfall components of the five forest types in Putuoshan Island, Zhejiang, East China (Data in parentheses are percentages)

\begin{tabular}{|c|c|c|c|c|c|}
\hline \multirow[t]{2}{*}{$\begin{array}{l}\text { 群落类型 } \\
\text { Community type }\end{array}$} & \multicolumn{5}{|c|}{ 组分调落量及占总凋落量百分比 } \\
\hline & 叶 Leaf & 枝 Twig & 花 Flower & 果 Fruit & 残体 Miscellaneous \\
\hline 枫香林 Liquidambar formosana forest & $2.73(68.23)$ & $0.35(8.62)$ & $0.19(4.83)$ & $0.56(14.05)$ & $0.17(4.27)$ \\
\hline 天竺桂+红楠林 Cinnamomum japonicum + Machilus thunbergii forest & $2.96(77.57)$ & $0.28(7.38)$ & $0.19(4.95)$ & $0.18(4.62)$ & $0.21(5.47)$ \\
\hline 马尾松林 Pinus massoniana forest & $3.09(78.50)$ & $0.15(3.72)$ & $0.17(4.21)$ & $0.18(4.49)$ & $0.36(9.08)$ \\
\hline 青冈林 Cyclobalanopsis glauca forest & $3.22(82.85)$ & $0.21(5.48)$ & $0.08(2.10)$ & $0.08(2.17)$ & $0.29(7.40)$ \\
\hline 台湾蚊母树林 Distylium gracile forest & $3.81(71.08)$ & $0.98(18.21)$ & $0.06(1.08)$ & $0.15(2.78)$ & $0.37(6.85)$ \\
\hline
\end{tabular}



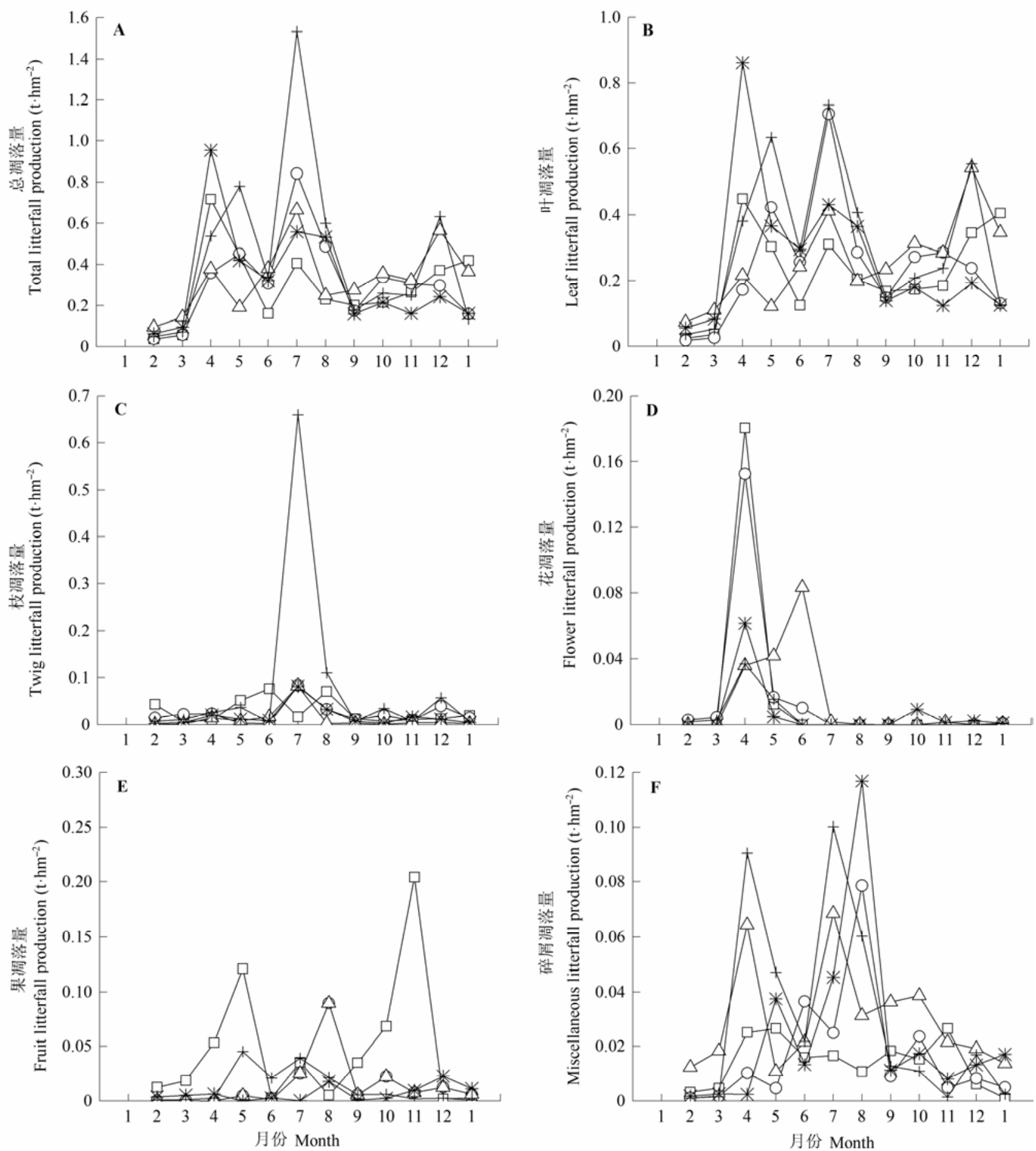

一——枫香林 Liquidambar formosana forest

一一一天答桂+红楠林 Machilus thunbergii + Cinnamomum japonicum forest

$\triangle \backsim$ 马尾松林 Pinus massoniana forest

米—青岗林 Cyclobalanopsis gluca forest

台湾蚁母树林 Distylium gracile forest

图1 浙江普陀山岛5种森林类型调落物季节动态。

Fig. 1 Seasonal dynamics of litterfall production of the five forest types in Putuoshan Island, Zhejiang.

4、7和12月份。在天竺桂+红楠林中, 森林上层风速、 下层风速以及空气湿度均出现 3 个峰值, 集中在 $4 、 7$ 和 12 月份; 土壤湿度有 2 个峰值, 分别在 3 月份和 7 月份。在青冈林中, 森林上层风速至少在7月份有一
个峰值, 森林下层风速至少有 2 个峰值, 即 7 月份和 12月份; 而湿度的月动态变化较小。在台湾蚊母树 林中, 仅森林上层风速出现 3 个峰值, 即 $4 、 7$ 以及 12 月份, 其余指标变化不大。在马尾松林中, 风速、湿 

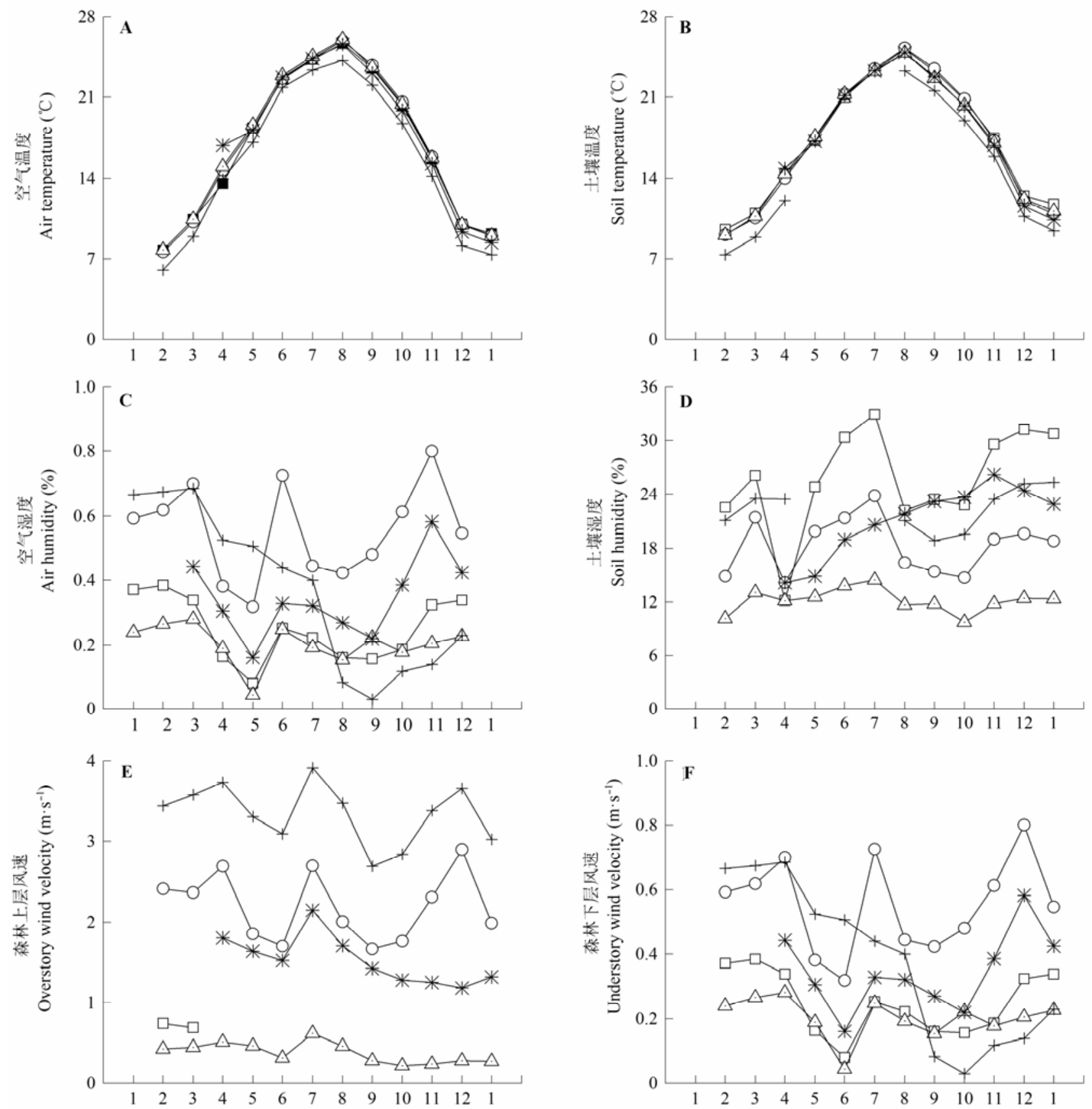

月份 Month

一—枫香林 Liquidambar formosana forest -O— 天㷦桂+红梢林 Machilus thunbergii + Cinnamomum japonicum forest

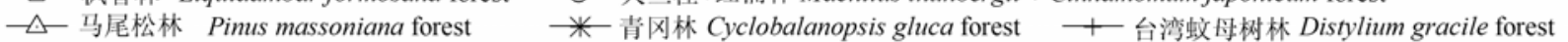

图2 浙江普陀山5种森林类型微气候月动态。

Fig. 2 Monthly dynamics of micro-climatic factors across the five forest types in Putuoshan Island, Zhejiang.

度变化不大。

\section{4 森林凋落量月动态与微气候之间的关系}

圥余分析结果表明: 森林调落量与空气温度、 空气湿度、森林上层风速有关 $(p<0.01$, 图3), 调落 量变异的12\%能被微气候因子所解释。影响各组分 凋落量的微气候因子存在差异, 枝凋落量仅受森林
上层风速的影响 $\left(F=4.06, p=0.04, R^{2}=0.05\right)$, 叶调 落量主要受空气温度的影响 $\left(F=5.56, p=0.03, R^{2}=\right.$ $0.09)$, 花调落量主要受空气湿度的负向效应的影响 $\left(F=7.79, p=0.01, R^{2}=0.13\right)$, 果凋落量主要受到空 气温度的影响 $\left(F=7.95, p<0.01, R^{2}=0.13\right)$, 碎屑凋 落量主要受到空气温度的影响 $(F=20.75, p<0.001$, 


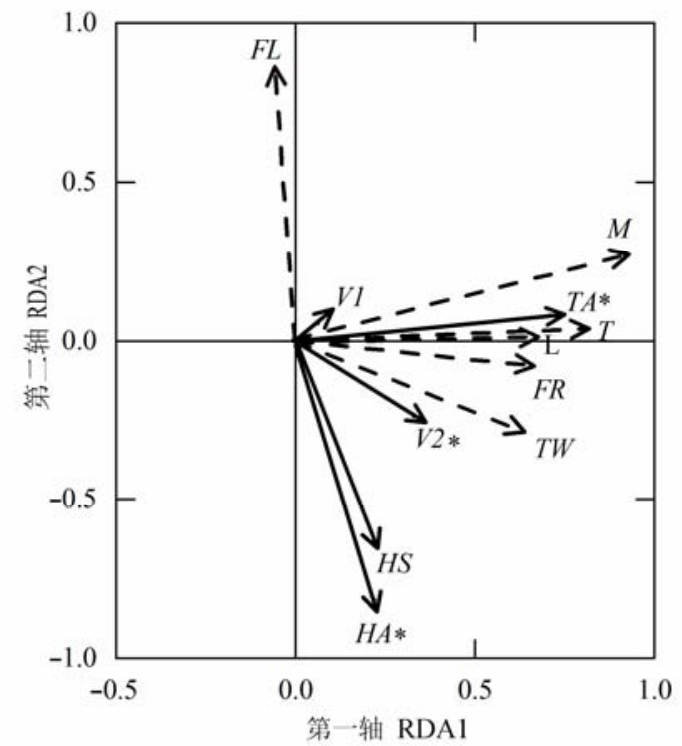

图3 浙江普陀山岛森林月总调落量及各组分与微气候因子 的圥余分析。实线向量为微气候因子, 虚线向量为森林月总 调落量及各组分。FL, FR, $H A, H S, L, M, T, T A, T W, V 1, V 2$ 分 别代表花、果、空气温度、空气湿度、土壤湿度、叶、碎屑、 总调落量、枝、森林下层风速和森林上层风速。*, $p<0.05$ 。 Fig. 3 Redundancy analyses (RDAs) calculated from monthly litterfall production (dash line vectors) in Putuoshan Island of Zhejiang and the monthly air temperature, air humidity, overstory wind velocity (bold line vectors) over one year. $F L$, flower litterfall production; $F R$, fruit litterfall production; $H A$, air humidity; $H S$, soil humidity; $L$, leaf litterfall production; $M$, miscellaneous; $T$, total litterfall production; $T A$, air temperature; $T W$, twig litterfall production; $V 1$, understory wind velocity; $V 2$, overstory wind velocity. ${ }^{*}, p<0.05$.

$\left.R^{2}=0.33\right)$, 总调落量主要受到空气温度的影响 $(F=$ $\left.9.31, p<0.01, R^{2}=0.16\right)$ 。方差分解结果表明, 微气 候因子解释了森林月调落量各组分变异的 $14 \%$, 而 森林类型对森林各组分月调落量无影响(对各组分 月调落量变异解释度为 0$)$ 。

\section{3 讨论}

\section{1 森林年凋落量及组分特征}

森林调落物是生态系统净初级生产力 $(N P P)$ 的 重要组成部分(Liu et al., 2004), 探索普陀山岛森林 调落量有助于研究区域的碳资源评估。研究表明, 大区域尺度范围内, 不同区域的森林年调落量存在 差异。本研究地点是典型海岛区域, 其森林年调落 量为3.45-5.36 t $\cdot \mathrm{hm}^{-2} \cdot \mathrm{a}^{-1}$, 在全球年凋落量范围之内 (3-11 $\mathrm{t} \cdot \mathrm{hm}^{-2} \cdot \mathrm{a}^{-1}$ )(Zhang et al., 2014); 与亚热带其他 区域相比，小于浙江天童常绿阔叶林(6.38-13.03 $\mathrm{t} \cdot \mathrm{hm}^{-2} \cdot \mathrm{a}^{-1}$ )(阎恩荣等, 2008), 大于广东南亚热带针 叶林 $\left(2.70 \mathrm{t} \cdot \mathrm{hm}^{-2} \cdot \mathrm{a}^{-1}\right)$ (翁轰等, 1993)。
森林年调落量各组分构成比例存在差异, 叶调 落量为最大组成部分, 与全球范围内调落量组成相 一致(Zhang et al., 2014)。通常叶调落量和枝调落量 所占比例最大(徐旺明等, 2013), 但在普陀山岛, 枝 调落量的比例并非完全大于其余各组分的比例。在 枫香林中, 果调落量 $>$ 枝调落量, 由于枫香群落主 要以枫香为主, 而枫香果实较大, 其质量也相对较 大, 此结果与物种的生物学特性相关。而徐旺明等 (2013)对湖南省森林植物园的森林调落物产量研究 发现, 枫香林的枝调落量大于果调落量。因此, 调落 物各组分的相对比例可能与地理位置有关。在青冈 林和台湾蚊母树林中, 调落枝量均小于碎屑量, 因 枝的调落可能随机性较大(徐旺明等, 2013), 每月收 集到的调落枝很可能来源于枯枝(Gosz et al., 1972), 在风和降雨等微气候影响下极易脱落。因此, 调落 枝的比例变化较大, 可能与微气候密切相关。

\section{2 森林月凋落量及其各组分动态特征}

枫香林、天竺桂+红楠林、青冈林的月调落总 量均表现出双峰型的特征, 其他两种为三峰型。森 林调落物季节动态模式可能是单峰型、双峰型、三 峰型或不规则型等, 峰值主要与森林调落节律及降 雨、温度和风速等微气候因子有关(Zhang et al., 2014)。普陀山岛森林月调落量受风的影响较大, 四 种林型的调落峰值和风速峰值趋势基本一致, 主要 集中在5月份、台风干扰较大的4月份以及“灿鸿”台 风强烈干扰的7月份和12月份(图1, 图2), 台风极有 可能加速了森林的调落过程。此外, 台风一般在夏 季发生, 并且调落峰值也主要出现在夏季(Sharma et al., 2012), 而本研究中, 7月份台风较大、温度较 高、新陈代谢的速度较快、叶片更新速率较快, 故5 种林分均在7月份出现的峰值可能与植物自身生理 代谢特性有关(图2, 图3),

徐旺明等(2013)在枫香林调落物研究中发现, 其调落特征属于单峰型, 主要与调落节律有关, 峰 值出现在枫香落叶期的10月份; 而本研究发现枫香 林在4月份出现第一个调落高峰, 在7月份达到第二 个调落高峰。因此, 枫香林月调落量受台风的影响可 能要大于自身生理生态的影响。马尾松林 3 个调落峰 值大小依次为: 7 月份 $>12$ 月份 $>4$ 月份, 其中12月份为 马尾松落叶期, 温度较低, 为了减少养分和水分的 消耗, 极易发生生理性调落(原作强等, 2010), 使得 调落量较大。台湾蚊母树林的峰值从大到小依次为7 
月份、 5 月份、12月份(图1), 12月份为调落期, 5月份 可能与物候有关, 由于大多数常绿阔叶林在春夏 (3-5月)期间生长旺盛, 萌发新叶, 促使了衰老 叶的 脱落(郭婧等, 2015), 因此在5月份出现第1个峰值。

\section{3 影响森林月凋落量的控制因子}

有关森林月调落量动态的研究已有较多, 并且 月调落动态大多与调落节律有关, 主要集中发生在 秋季和冬季(Sharma et al., 2012; 徐旺明等, 2013; Zhang et al., 2014); 但是, 在区域尺度上, 关于温 度、湿度、风速等微气候对不同调落物组分的影响 还很少有报道。调落物不同组分的调落量受环境因 子的影响而存在差异。

本研究表明, 研究区域森林月调落量与森林类 型无关, 而与微气候因子有关。森林月调落总量和 叶调落量、果调落量、碎屑调落量受到空气温度的 正向作用的影响(图3), 叶调落量月动态与风速月动 态变化趋势一致(图1, 图2), 但并未受风速的影响, 而与空气温度有关; 枝调落量受森林上层风速的影 响最大, 随风速的增加而增大, 并且与风速变化相 一致(图1, 图2)。普陀山岛地区台风主要在夏季发 生, 枝条的调落与台风密切相关, 在海岛这种伴有 台风影响的特殊生境下, 枝条因机械阻力而发生调 落, 尤其是树干上残留的枯死枝(Gosz et al., 1972; Sharma et al., 2012)。

温度越高, 叶片越容易脱落, 这可能与抽枝物 候这一现象有关。抽枝物候是指植物在一年的生长 过程中, 随着气候的季节性变化而发生规律性变化 的现象, 伴随着新枝条发生和伸长的过程, 由于叶 片着生在枝条上, 因此抽枝和展叶过程在时间和空 间上是相互联系的(Dale, 1982; 夏洋洁等, 2013)。南 方常绿阔叶林与北方森林相比较为特殊, 存在二次 抽枝情况, 发生在夏末秋初, 并且第二次抽枝时展 叶初期温度较高, 抽枝与物种所处的气候环境有关, 所以所有物种展叶速率较快(夏洋洁等, 2013), 叶片 更新更快, 而植物叶片的损失发生在展叶初期 (Coley \& Barone, 1996), 抽枝过程伴随着叶片的大 量调落。此外, 植物处于高温环境下, 光合作用强, 处于生长旺季, 萌发新叶, 叶片更新快, 促使衰老 的叶子脱落(郭婧等, 2015)。南方常绿润叶林虽然生 活于湿润环境下, 但是温度较高时, 叶片蒸腾作用 较强, 丧失大量水分, 因此为了维持自身生理活动 需要的水分, 就通过调落叶片减少水分丧失, 发生
生理性脱落(Valentini et al., 2008; Ndakara, 2011; Zhang et al., 2014)。

影响不同区域范围内枝调落的微气候因素存在 差异。有关东北林区和湖南森林调落物的研究发现, 枝的调落主要与温度和降雨有关(张新平等, 2008; 徐旺明等, 2013); 而Sharma等(2012)对日本岛上亚 热带地区的森林调落量的研究表明, 枝调落量与空 气温度和风速正相关, 与湿度无关, 我们的研究结 果(图4B)与此相一致, 可见湿度并不能控制枝的调 落过程。而总调落量主要由叶构成(徐旺明等, 2013), 碎屑凋落量主要来源于残存的叶片, 因此影响总调 落量和碎屑组分调落量的控制因子相一致, 均为空 气温度。繁殖器官的调落量主要与树种的繁殖特性 和年降水量有关(张新平等, 2008)。本研究中, 繁殖 器官花调落量受到空气湿度负效应的影响(图4), 原 因可能是研究区域的花可能对湿度的容忍性强, 较 大的湿度促进了繁殖器官的发育, 满足了器官发育 对水分的需求, 构建了稳定的器官; 而较低的湿度 代表植物处于水分相对缺乏的生境中, 因此不能保 证繁殖器官的正常发育, 而发生生理性调落 (Borchert, 1996)。

综上所述: 不同的森林类型对森林凋落量不存 在影响, 森林月调落量随空气温度的增高而增大。 影响不同组分的月调落量的微气候因子存在差异, 叶、果及碎屑凋落量主要受空气温度的影响, 并且 随空气温度的增高而增大; 枝调落量随着森林上层 风速的增大而增大, 与温度无关; 花的调落随空气 湿度的增大而减小, 说明森林不同凋落物组分的资 源分配受不同环境因子的影响(张新平等, 2008)。然 而, 微气候只是有限地调节森林调落过程, 调落过 程还受到物候和森林主要树种的生物学特性制约 (温光远等, 1989; 邹碧等, 2006; 张新平等, 2008)。 本文尚未考虑物种类型及深入研究主要树种的生物 生理学调落机制, 亟待进一步的实验探索。

基金项目 国家自然科学基金 (31270475和 31070383)。

致谢 感谢华东师范大学何东、许洺山、张晴晴、 赵延涛、周刘丽、周贵尧等同学在野外收集数据和 室内分析中给予的帮助。

\section{参考文献}

Berg B, Meentemeyer V (2001). Litter fall in some European 
coniferous forests as dependent on climate: A synthesis. Canadian Journal of Forest Research, 31, 292-301.

Borchert R (1996). Phenology and flowering periodicity of neotropical dry forest species: Evidence from herbarium collections. Journal of Tropical Ecology, 12, 65-80.

Brando PM, Nepstad DC, Davidson EA, Trumbore SE, Ray D, Camargo P (2008). Drought effects on litterfall, wood production and belowground carbon cycling in an Amazon forest: Results of a through fall reduction experiment. Philosophical Transactions of the Royal Society of London, 363, 1839-1848.

Chi Y, Shi HH, Guo Z, Ding DW (2015). Connotation, features and causes of island ecological vulnerability. Acta Oceanologica Sinica, 37, 93-105. (in Chinese with English abstract) [池源, 石洪华, 郭振, 丁德文 (2015). 海 岛生态脆弱性的内涵、特征及成因探析. 海洋学报, 37, 93-105.]

Coley PD, Barone JA (1996). Herbivory and plant defenses in tropical forests. Annual Review of Ecology and Systematics, 27, 305-335.

Dale JE (1982). The Growth of Leaves. Edward Arnold Limited, London. 31-41.

Friend A, Stevens A, Knox R, Cannell M (1997). A processbased, terrestrial biosphere model of ecosystem dynamics (Hybrid v3.0). Ecological Modelling, 95, 249-287.

Gosz JR, Likens GE, Bormann FH (1972). Nutrient content of litterfall on the Hubbard Brook experimental forest, New Hampshire. Ecology, 1972, 769-784.

Gross J (2003). Variance inflation factors. R News, 3, 13-15.

Guo J, Yu LH, Fang X, Xiang WH, Deng XW, Lu X (2015). Litter production and turnover in four types of subtropical forests in China. Acta Ecologica Sinica, 35, 4668-4677. (in Chinese with English abstract) [郭婧, 喻林华, 方晰, 项文化, 邓湘雯, 路翔 (2015). 中亚热带4种森林调落 物量、组成、动态及其周转期. 生态学报, 35, 46684677.]

Hoque MM, Mustafa Kamal AH, Idris MH, Haruna Ahmed O, Rafiqul Hoque ATM, Masum Billah M (2015). Litterfall production in a tropical mangrove of Sarawak, Malaysia. Zoology and Ecology, 25, 157-165.

Legendre P, Oksanen J, ter Braak CJF (2011). Testing the significance of canonical axes in redundancy analysis. Methods in Ecology and Evolution, 2, 269-277.

Lin KC, Hamburg SP, Tang S, Hsia YJ, Lin TC (2011). Typhoon effects on litterfall in a subtropical forest. Canadian Journal of Forest Research, 33, 2184-2192.

Liski J, Nissinen A, Erhard M, Taskinen O (2003). Climatic effects on litter decomposition from arctic tundra to tropical rainforest. Global Change Biology, 9, 575-584.

Liu CJ, Westman CJ, Berg B, Kutsch W, Wang GZ, Man RZ, Ilvesniemi H (2004). Variation in litterfall-climate relationships between coniferous and broadleaf forests in
Eurasia. Global Ecology and Biogeography, 13, 105-114.

Lovett GM, Christenson LM, Groffman PM, Jones CG, Hart

JE, Mitchell MJ (2010). Insect defoliation and nitrogen cycling in forests. Bioscience, 52, 335-341.

Ma WJ, Zhao YT, Zhang QQ, Arshad A, Shi QR, Yan ER (2014). C:N:P stoichiometry in forest floor litter of evergreen broad-leaved forests at different successional stages in Tiantong, Zhejiang, eastern China. Chinese Journal of Plant Ecology, 38, 833-842. (in Chinese with English abstract) [马文济, 赵延涛, 张晴晴, Ali Arshad, 史青茹, 阎恩荣 (2014). 浙江天童常绿阔叶林不同演替阶段地 表调落物的 C:N:P化学计量特征. 植物生态学报, 38, 833-842.]

Ndakara OE (2011). Litterfall and nutrient returns isolated stands of Persea gratissima (Avocado pear) in the rainforest zone of southern Nigeria. Ethiopian Journal of Environmental Studies and Management, 4, 42-50.

Ning XB, Xiang WH, Wang GJ, Fang X, Yan WD, Deng XW (2009). Litterfall production and dynamic for twenty years of a successive replanting Cunninghamia lanceolata plantation at Huitong, Hunan. Acta Ecologica Sinica, 29, 5122-5129. (in Chinese with English abstract) [宁晓波, 项文化, 王光军, 方晰, 问文德, 邓湘雯 (2009). 湖南 会同连作杉木林调落物量20年动态特征. 生态学报, 29 , 5122-5129.]

Oksanen J, Kindt R, Legendre P, O’Hara B, Stevens MHH, Oksanen MJ, Suggests MASS (2007). The vegan Package. Community Ecology Package, 10, 631-637.

Olena P, Nedret B (2007). Impact of deciduous tree species on litterfall quality, decomposition rates and nutrient circulation in pine stands. Forest Ecology and Manage- ment, 253, 11-18.

Qian YF, Yin LT, Hu JF, Zhang C, Yu SQ, Shen YL, Peng DQ (2012). Niche characteristics of main plant species in Putuo Mountain, Zhejiang Province of East China. Chinese Journal of Ecology, 31, 561-568. (in Chinese with English abstract) [钱逸凡, 伊力塔, 胡军飞, 张超, 余树全, 沈 摇露, 彭东琴 (2012). 普陀山主要植物种生态位特征. 生态学杂志, 31, 561-568.]

Running SW, Hunt ER Jr. (1993). Generalization of a forest ecosystem process model for other biomes, Biome-BGC, and an application for global-scale models. In: Ehleringer JR, Field C eds. Scaling Physiological Processes: Leaf to Globe. Academic Press, San Diego, USA.

Scherer-Lorenzen M, Bonilla JL, Potvin C (2007). Tree species richness affects litter production and decomposition rates in a tropical biodiversity experiment. Oikos, 116, 21082124.

Sharma S, Hoque ATMR, Analuddin K, Hagihara A (2012). Litterfall dynamics in an overcrowded mangrove Kandelia obovata (S., L.) Yong stand over five years. Estuarine Coastal and Shelf Science, 98, 31-41. 
Thuille A, Schulze ED (2006). Carbon dynamics in successsional and afforested spruce stands in Thuringia and the Alps. Global Change Biology, 12, 325-342.

Valentini CMA, Sanches L, de Paula SR, Vourlitis GL, Nogueira JD, Pinto OB, Lobo FD (2008). Soil respiration and aboveground litter dynamics of a tropical transitional forest in northwest Mato Grosso, Brazil. Journal of Geophysical Research: Biogeosciences, 113, G00B10. doi: 10.1029/2007JG000619.

Wang HC, Lin KC, Huang CY (2016). Temporal and spatial patterns of remotely sensed litterfall in tropical and subtropical forests of Taiwan. Journal of Geophysical Research Biogeosciences, 121, 509-522.

Wen YG, Wei BE, Li JJ (1989). A study on the litter production and dynamics of subtropical forest. Scientia Silvae Sinicae, 25, 542-547. (in Chinese with English abstract) [温远光, 韦炳二, 黎洁娟 (1989). 亚热带森林调落物产量及动态 的研究. 林业科学, 25, 542-548.]

Weng H, Li ZA, Tu MZ, Yao WH (1993). The production and nutrient contents of litter in forests of Dinghushan mountain. Acta Phytoecologica Sinica, 17, 299-304. (in Chinese with English abstract) [翁轰, 李志安, 屠梦照, 姚文华 (1993). 鼎湖山森林调落物量及营养元素含量研究. 植 物生态学报, 17, 299-304.]

Xia YJ, Tang JQ, Zhang GF, Huang C, Meng FQ, Sun SC (2013). First and second sets of shoots in five evergreen woody species from Tiantong National Forest Park of Zhejiang, China. Chinese Journal of Plant Ecology, 37, 220-229. (in Chinese with English abstract) [夏洋洁, 唐 坚强, 张光富, 黄超, 蒙风群, 孙书存 (2013). 浙江天 童国家森林公园5种常绿阔叶植物的一次和二次抽枝进 程. 植物生态学报, 37, 220-229.]

Xu WM, Yan WD, Li JB, Zhao J, Wang GJ (2013). Amount and dynamic characteristics of litterfall in four forest types in subtropical China. Acta Ecologica Sinica, 33, 7570-7575. (in Chinese with English abstract) [徐旺明, 间文德, 李洁冰, 赵晶, 王光军 (2013). 亚热带4种森林 调落物量及其动态特征. 生态学报, 33, 7570-7575.]

Xu XN, Hirata E, Shibata H (2004). Effect of typhoon disturbance on fine litterfall and related nutrient input in a subtropical forest on Okinawa Island, Japan. Basic and Applied Ecology, 5, 271-282.

Yan ER, Wang XH, Zhou W (2008). Characteristics of litterfall in relation to soil nutrients in mature and degraded evergreen broad-leaved forests of Tiantong, east China. Journal of Plant Ecology (Chinese Version), 32, 1-12. (in Chinese with English abstract) [阎恩荣, 王希华, 周武 (2008). 天童常绿阔叶林不同退化群落的调落物特征及 与土壤养分动态的关系. 植物生态学报, 32, 1-12.]
Yuan ZQ, Li BH, Bai XJ, Lin F, Shi S, Ye J, Wang XG, Hao ZQ (2010). Composition and seasonal dynamics of litterfalls in a broad-leaved Korean pine (Pinus koraiensis) mixed forest in Changbai Mountains, Northeast China. Chinese Journal of Applied Ecology, 21, 2171-2178. (in Chinese with English abstract) [原作强, 李步杭, 白雪娇, 落菲, 师帅, 叶吉, 王绪高, 郝占庆 (2010). 长白山阔 叶红松林凋落物组成及其季节动态. 应用生态学报, 21 , 2171-2178.]

Zhang HC, Yuan WP, Dong WJ, Liu SG (2014). Seasonal patterns of litterfall in forest ecosystem worldwide. Ecological Complexity, 20, 240-247.

Zhang QQ, Zhou LL, Zhao YT, Xu MS, Yan ER (2016). Litter dynamics of plants in a successional series of evergreen broad-leaved forests in Tiantong region, Zhejiang Province. Chinese Journal of Ecology, 35, 290-299. (in Chinese with English abstract) [张晴晴, 周刘丽, 赵延涛, 许 洺山, 阎恩荣 (2016). 浙江天童常绿阔叶林演替系列植 物叶片的调落节律. 生态学杂志, 35, 290-299.]

Zhang XP, Wang XP, Zhu B, Zong ZJ, Peng CH, Fang JY (2008). Litterfall production in relation to environmental factors in northeast China's forests. Journal of Plant Ecology (Chinese Version), 32, 1031-1040. (in Chinese with English abstract) [张新平, 王襄平, 朱彪, 宗占江, 彭长辉, 方精云 (2008). 我国东北主要森林类型的调落 物产量及其影响因素. 植物生态学报, 32, 1031-1040.]

Zhao CL, Ou DY, Hu JF, Zhou WP, Zhao Y (2009). Resource evaluation and protection countermeasure of ancient and famous trees in Putuo Mountain. Journal of Zhejiang Ocean University (Natural Science), 28, 200-204. (in Chinese with English abstract) [赵慈良, 欧丹燕, 胡军飞, 周伟平, 赵颖 (2009). 普陀山古树名木资源评价与保护 对策. 浙江海洋学院学报: 自然科学版, 28, 200-204.]

Zheng Z, Li YR, Liu HM, Feng ZL, Gan JM, Kong WJ (2005). Litterfall of tropical rainforests at different altitudes, Xishuangbanna, Southwest China. Acta Phytoecologica Sinica, 29, 884-893. (in Chinese with English abstract) [郑 征, 李佑荣, 刘宏茂, 冯志立, 甘建民, 孔维静 (2005). 西双版纳不同海拔热带雨林调落量变化研究. 植物生 态学报, 29, 884-893.]

Zou B, Li ZA, Ding YZ, Tan WN (2006). Litterfall of common plantations in south subtropical China. Acta Ecologica Sinica, 26, 715-721. (in Chinese with English abstract) [邹 碧, 李志安, 丁永祯, 谭万能 (2006). 南亚热带4种人工 林调落物动态特征. 生态学报, 26, 715-721.]

特邀编委: 代力民 责任编辑: 王 葳 


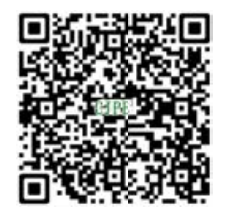

植物生态学报官网

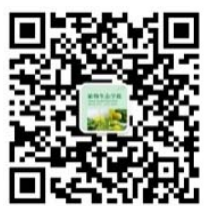

微信订阅号

期刊及学科

相关信息发布

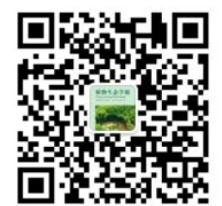

微信服务号

稿件状态查询

全文检索汶览 